\title{
PENGARUH DOSIS PUPUK KASCING DAN NITROGEN TERHADAP PERTUMBUHAN DAN HASIL TANAMAN SELADA (LACTVCA SATIVA L.) VAR GEORGIA
}

\author{
Ketut Turaini Indra Winten \\ Fakultas Pertanian Universitas Tabanan Bali \\ nusiwinten@vahoo.co.id
}

\begin{abstract}
The Effects of Casting Fertilizer and Nitrogen Rates on the Growth and Yields of Lettuce (Lactuca sativa 1.) Var. Georgia

The low of growth and yield of lettuce is quite often caused by the low of soil fertility, especially nitrogen and C-organic content. Poor soil physical properties also contribute to the cause of low yield of lettuce. Improved soil physical and chemical properties by adding casting fertilizers and nitrogen are expected to be able to increase the yields of lettuce.

The field experiment was conducted in Candikuning village, district of Baturiti, Tabanan regency, from October 2005 to January 2006. The objective of experiment was to study the effect of casting fertilizer and nitrogen rates on the growth and yields of lettuce. A randomize complete block design was used in this experiment and two treatment factors were imposed. Those two treatment factors were rates of casting fertilizers (i.e. $0,10,20$ and $30 \mathrm{t} \mathrm{ha"}^{11}$ ) and rates of $\mathrm{N}$ (i.e. 0, 92, 138 and $184 \mathrm{~kg} \mathrm{~N}$ ha"l $^{1}$ ), which were arranged factorially and repeated three times.

Results of experiment indicated that interaction between casting fertilizer and nitrogen rates did not significantly affect the yields of lettuce. The rates of $\mathrm{N}$ only significantly affected several growth variables and the oven dry weight of heads plant"1. Increased rates of $\mathrm{N}$ from 0 to $92 \mathrm{~kg} \mathrm{~N}^{\text {h"1 }}$ significantly resulted in the oven dry weight of heads of $2.798 \mathrm{~g}$ plant" ${ }^{1}$ which was $13.9 \%$ higher than that of $0 \mathrm{~kg} \mathrm{~N}$ ha"1. Rates of casting fertilizer significantly affected head diameter and the oven dry weight of heads plant"1 and ha"1. Increased rates of casting fertilizer from 0 to $10 \mathrm{t}$ ha" ${ }^{11}$ gave the oven dry weight of heads as much as $0.232 \mathrm{t} \mathrm{ha"}^{11}$ or $9.43 \%$ higher than the weight given by rate of $0 \mathrm{t} \mathrm{ha}^{\prime 1}$. The effects of rates of casting fertilizer and $\mathrm{N}$ were only significant on several soil physical properties.

The relationship between rates of casting fertilizer and yields of lettuce was quadratic $(\mathrm{Y}=$ $\left.0.21135+0.0032 \mathrm{X}-0.001 \mathrm{X}^{2} ; \mathrm{R}^{2}=0.981\right)$. The optimum rate of casting fertilizer was $16.0 \mathrm{t}$ ha- 1 with maximum oven dry weight of heads of $0.237 \mathrm{t}$ ha"1, meanwhile the optimum rate of $\mathrm{N}$ had not obtained in this experiment.
\end{abstract}

Key words: Casting fertilizer, Nitrogen, Growth, Yield, Lettuce (Lactuca sativa L.)

\section{PENDAHULUAN}

Tanaman selada (Lactuca sativa L. ) var. Georgia termasuk jenis sayuran daun yang bernilai gizi tinggi yaitu terutama kandungan vitamin, mineral, dan mempunyai nilai ekonomi tinggi. Selada dapat dibudidayakan di dataran tinggi maupun dataran rendah, tetapi hampir sebagian besar tanaman selada diusahakan di dataran tinggi, terutama jenis selada krop (Rukmana, 1994 ; Haryanto dkk ., 2003).

Berbagai upaya pengembangan tanaman selada telah dilakukan namun masih belum mampu memenuhi permintaan pasar. Permintaan selada krop di daerah Bali sebanyak 144 - $180 \mathrm{t}$ th"', sedangkan potensi hasil yang bisa dicapai di daerah Candikuning 17-18 t ha" $^{\prime 1}$ th"'(Anon., 2004). Hal ini karena cara budidaya selada yang dilakukan petani belum tepat terutama dari segi pemupukan baik pupuk organik maupun anorganik. Hal ini ditunjukan oleh kandungan C - organik tanah termasuk rendah 1,88\% (Lampiran. 1). Secara ideal kandungan bahan organik yang ada di dalam tanah adalah berkisar antara $3-5 \%$, oleh karena itu perlu penambahan bahan organik yang tepat.

Kascing merupakan salah satu pupuk organik yang dapat meningkatkan aktivitas mikroorganisme, juga berperan dalam menambah unsur hara serta mempercepat ketersediaan unsur hara bagi tanaman, disamping memantapkan agregat tanah serta dapat meningkatkan bahan organik tanah (Kartini, 2000; Mulat, 2003). Kascing sebagai salah satu pupuk organik dapat memelihara serta meningkatkan kesuburan tanah secara berkelanjutan (Untung, 1997). Kascing sebagai pupuk organik sudah banyak ditemukan di pasar sebagai produk perusahaan, tetapi petani sudah memproduksi sendiri pupuk kascing sejak tahun 2002, produksi pupuk kascing petani mengandung C-organik $(16,54 \%), \quad \mathrm{N}$ total $(1,89 \%)$ (Tabel. 1) 
Tabel 1. Hasil analisis tanah dan kascing di dusun Pemuteran desa Candikuning

\begin{tabular}{lclcl}
\hline Jenis analisis (tanah) & Nilai & Keterangan & (Kascing) & Keterangan \\
\hline pH tanah & 6,1 & Agak masam & 8,1 & Agak alkali \\
C-Organik (\%) & 1,88 & Rendah & 16,54 & Sangat tinggi \\
N-Total (\%) & 0,27 & Sedang & 1,89 & Rendah \\
P-Tersedia(mgkg") & 97,34 & Sangat tinggi & 0,53 & Rendah \\
K-Tersedia(me/100g) & 0,28 & Rendah & 1.11 & Rendah \\
KTK (me/lOOg) & 13.34 & Rendah & 62,02 & Sangat tinggi \\
BO $\{\%)$ & 3,25 & Tinggi & 28,62 & Sangat tinggi \\
Kadar air (\%) & 28 & & 68 & \\
Tekstur (\%): & Pasir berlempung & & & \\
- Pasir & 79,76 & & & \\
-Debu & 19,10 & & & \\
- Li at & 1.14 & & & \\
\hline
\end{tabular}

Sumber: Laboratorium Kimia Tanah, Jurusan Tanah, Fakultas Pertanian Universitas

Brawijaya, September 2005

Penelitian tentang pupuk kascing pada tanaman sayuran sudah dilakukan, tetapi belum dilakukan pada tanaman selada. Penelitian pupuk kascing yang berasal dari daerah Candikuning telah dilakukan di Desa Antapan Baturiti pada tanaman kentang, di dapatkan rata - rata berat total umbi segar kentang diperoleh $14,42 \mathrm{t} \mathrm{ha}^{11}$ pada pemupukan kascing dengan dosis $5 \mathrm{t} \mathrm{ha"1}^{11}$ (Karnata, 2004).

Selada merupakan tanaman sayuran yang sangat banyak membutuhkan unsur $\mathrm{N}$ untuk menghasilkan kualitas (kesegaran, warna daun) dan kuantitas hasil yang tinggi. Urea merupakan pupuk anorganik yang mempunyai si fat sangat labil yaitu mudah menguap, mudah larut sehingga akibatnya tanaman akan selalu kekurangan unsur $\mathrm{N}$ (Buckman dan Brady, 1982; Haryanto, dkk., 2003) terutama pada tanah pasir berlempung seperti di daerah Candikuning dengan curah hujan tinggi 244.5 mm bin "' tahun 2004 . Untuk meningkatkan KTK pada tanah pasir berlempung memerlukan tambahan bahan organik yang tinggi sehingga $\mathrm{N}$ yang diberikan akan dapat dipegang dan tersedia bagi tanaman (Nurhajati, dkk., 1986). Penelitian Sukerta (2004) di lahan kering Desa Jungutbatu Nusa Penida menggunakan $138 \mathrm{~kg}$ $\mathrm{N}$ ha"' (300 kg urea ha"1) yang dikombinasikan dengan 25 t kascing ha"' menghasilkan berat total segar tanaman sawi sebesar 238,52 t ha"1.

-Penelitian pemberian pupuk kascing dan nitrogen pada tanaman selada belum banyak dilakukan di Candikuning oleh karena itu perlu dilakukan penelitian dosis pupuk kascing dan nitrogen terhadap hasil tanaman selada (Lactuca sativa L. ) var. Georgia. Adapun tujuan penelitian mengkaji pengaruh dosis pupuk kascing dan nitrogen terhadap hasil tanaman selada di Desa Candikuning.
Hipotesis yang diajukan adalah untuk memperoleh dosis pupuk kascing dan nitrogen yang optimum terhadap hasil tanaman selada.

\section{BAHAN DAN METODE}

Penelitian ini dilaksanakan di Dusun Pemuteran, Desa Candikuning, Kecamatan Baturiti, Kabupaten Tabanan, Bali. Pada ketinggian tempat $\pm 1247 \mathrm{~m}$ diatas permukaan laut. Penelitian berlangsung dari tanggal 23 Oktober 2005 sampai dengan 21 Januari 2006 dari pengolahan tanah, sampai panen. Daerah Candikuning termasuk daerah beriklim basah dengan sembilan bulan basah dan tiga bulan kering tahun 2005 (Tabel 3).

Penelitian ini menggunakan Rancangan Acak Kelompok. (RAK) dengan dua faktor yang disusun secara faktorial. Sebagai faktor pertama adalah dosis pupuk kascing (K) yang terdiri dari 4 tingkat yaitu $\mathrm{K}_{\mathrm{o}}$ ( $0 \mathrm{t}$ ha"' pupuk kascing ), Ki (10 t ha"' pupuk kascing), $\mathrm{K}_{2} \quad\left(20 \mathrm{t}\right.$ ha" ${ }^{11}$ pupuk kascing ), $\mathrm{K}_{3}$ ( $30 \mathrm{t}$ ha"1 pupuk kascing ).

Sebagai faktor kedua adalah dosis nitrogen (N) yaftg terdiri dari 4 tingkat yaitu $\mathrm{N}_{\mathrm{o}}: 0 \mathrm{~kg} \mathrm{~N}$ ha" ${ }^{1}$ (0 kg urea ha"' ), N,: $92 \mathrm{~kg} \mathrm{~N}$ ha"1 (200 kg urea ha"'), $\mathrm{N}_{2}$ : $138 \mathrm{~kg} \mathrm{~N}$ ha"' (300 kg urea ha"' ), $\mathrm{N}_{3}$ : $184 \mathrm{~kg} \mathrm{~N}$ ha"1 (400 kg urea ha"1 ), masing masing diulang tiga kali. Selada krop yang dipakai adalah varietas Georgia. Pupuk yang digunakan adalah pupuk kascing sesuai perlakuan yang diperoleh dari petani setempat. Pupuk anorganik yang diberikan adalah urea sesuai perlakuan, $150 \mathrm{~kg} \mathrm{KCI} \mathrm{ha"1} \mathrm{(sesuai} \mathrm{anjuran).}$ Untuk mencegah hama dan penyakit digunakan insektisida Sherpa 50 EC (10.ml 121 air" $\left.^{11}\right)$, dan fungisida Daconil $75 \mathrm{WP}$ ( $10 \mathrm{ml} 121$ air"' ), Acrobat 50 WP (5 g 121 air"' ) dan Borer sebagai lem perekat (10 ml 121 air" $\left.^{\prime 1}\right)$. Pengendalian gulma dilakukan dengan mencabut gulma yang 
tumbuh disekitar lobang tanam dan pada larikan antara petak perlakuan.

Pembuatan petak secara keseluruhan dilakukan satu bulan sebelum tanam, dibuat petak- petak dengan ukuran $2,7 \mathrm{~m}$ x $1,2 \mathrm{~m}$ sebanyak 48 petak. Jarak antar ulangan $50 \mathrm{~cm}$ dan jarak antar petak $30 \mathrm{~cm}$ dengan tinggi petak $\pm 20 \mathrm{~cm}$. Pupuk kascing diberikan bersamaan dengan pembuatan petak, dengan cara ditaburkan di atas guludan dalam petak percobaan, selanjutnya ditaburi $\mathrm{KC} 1$ dan dipasangi mulsa plastik perak hitam serta dilubangi sesuai jarak tanam $30 \mathrm{~cm}$ x $30 \mathrm{~cm}$. Pemupukan $\mathrm{N}$ cara tugal diantara lubang tanam pada jarak $5-10 \mathrm{~cm}$, yang dilakukan pada 10 list, 20 list dan 30 hst .

Pesemaian benih diletakkan ,;pada tempat teduh selama \pm 15 hari dari saat sebar benih. Penanaman dilakukan dengan cara meletakkan bibit dalam lubang dengan kedalaman $5 \mathrm{~cm}$ di bawah rata-rata permukaan tanah di tengah - tengah lubang mulsa plastik perak hitam. Bibit yang ditanam dipilih yang seragam. tegar. kuat dan sehat serta telah memiliki 4 helai daun. Jika interaksi perlakuan berpengaruh nyata terhadap variabel yang diamati maka dilanjutkan dengan uji berganda Duncan pada taraf $5 \%$ tetapi bila interaksi tidak nyata maka dilanjutkan dengan uji BNT taraf $5 \%$ untuk pengaruh faktor tunggal. Untuk mengetahui hubungan antara dosis pupuk kascing dan nitrogen (X) pada berat kering oven krop ha"1 (Y) dilakukan analisis regresi (Gomez dan Gomez. 1995).

\section{HASIL DAN PEMBAHASAN}

Hasil analisis statistika menunjukkan bahwa interaksi antara dosis pupuk kascing dan dosis $\mathrm{N}$ tidak berpengaruh nyata terhadap pertumbuhan dan hasil selada. Dosis pupuk kascing hanya berpengaruh nyata terhadap berat kering oven krop tan"' dan ha"1 dan indeks panen. Sedang Dosis pupuk $\mathrm{N}$ berpengaruh nyata hanya terhadap berat kering oven krop tan"1. Perlakuan dosis pupuk kascing berpengaruh sangat nyata terhadap berat kering oven krop $\tan ^{11}$ dan ha"1 (Tabel 2). Peningkatan dosis pupuk kascing dari 0 menjadi $10 \mathrm{t}$ ha"' memberikan berat kering oven krop sebesar 0,232 t ha"', yaitu meningkat sebesar $9,43 \%$. Nilai tersebut tidak berbeda nyata dengan nilai pada perlakuan dosis 20 dan $30 \mathrm{t}$ ha"1. Ini berarti bahwa dosis $10 \mathrm{t}$ ha" $^{11}$ sudah cukup meningkatkan hasil selada pada tanah percobaan ini (kadar C- organik 1,88\% tergolong rendah) ( Tabel 1.) dan peningkatan dosis kascing selanjutnya tidak memberikan peningkatan hasil lagi. Walaupun berat kering oven krop $\tan ^{\prime 1}$ dan ha"' dipengaruhi oleh dosis pupuk kascing, ternyata berat segar krop $\tan ^{11}$ dan ha"' tidak dipengaruhi oleh perlakuan tersebut.

Tabel. 2 Pengaruh tunggal dosis pupuk kascing dan $\mathrm{N}$ terhadap saat terbentuk krop, saat tan saling menutupi, diameter krop , berat segar krop ( $\mathrm{g}$ tan"') ( $\left.\mathrm{t} \mathrm{ha}^{11}\right)$

\begin{tabular}{|c|c|c|c|c|c|}
\hline Perlakuan & $\begin{array}{c}\text { Saat terbentuk } \\
\text { krop } \\
\text { (hst) }\end{array}$ & $\begin{array}{l}\text { Saat tan saling } \\
\text { menutupi } \\
\text { hst }\end{array}$ & $\begin{array}{c}\text { Diameter } \\
\text { krop } \\
\mathrm{cm}\end{array}$ & $\begin{array}{l}\text { Berat segar } \\
\left(\mathrm{g} \tan ^{\prime \prime}\right)\end{array}$ & $\begin{array}{l}\text { krop } \\
(\mathrm{t} \mathrm{ha"1)})\end{array}$ \\
\hline \multicolumn{6}{|c|}{ Dosis pupuk kascing ( $\mathrm{t}$ ha"1) } \\
\hline 0 & 41,9 a & 41,5 a & $13,06 \mathrm{~b}$ & $176,1 \mathrm{a}$ & $14,92 \mathrm{a}$ \\
\hline 10 & 41,1 a & 41,1 a & $13,71 \mathrm{ab}$ & $210,0 \mathrm{a}$ & $16,01 \mathrm{a}$ \\
\hline 20 & 40,7 a & 41,9 a & 14,12 a & $198,2 \mathrm{a}$ & $16,14 \mathrm{a}$ \\
\hline 30 & $40,2 \mathrm{a}$ & $39,0 \mathrm{~b}$ & $14,14 \mathrm{a}$ & $211,0 \mathrm{a}$ & $17,33 \mathrm{a}$ \\
\hline BNT 5\% & - & 1,774 & 0,839 & - & - \\
\hline \multicolumn{6}{|c|}{ Dosis N (kg ha"1) } \\
\hline 0 & $42,3 \mathrm{a}$ & $41,5 \mathrm{a}$ & $13,55 \mathrm{a}$ & $174,0 \mathrm{a}$ & $15,25 \mathrm{a}$ \\
\hline 92 & $39,4 \mathrm{a}$ & 39,7 a & $13,79 \mathrm{a}$ & $197,1 \mathrm{a}$ & $16,00 \mathrm{a}$ \\
\hline 138 & 40,2 a & $40,2 \mathrm{a}$ & $13,78 \mathrm{a}$ & $207,0 \mathrm{a}$ & $16,08 \mathrm{a}$ \\
\hline 184 & $41,9 \mathrm{a}$ & $41,5 \mathrm{a}$ & $13,90 \mathrm{a}$ & $216,1 \mathrm{a}$ & $17,07 \mathrm{a}$ \\
\hline BNT 5\% & - & - & - & - & - \\
\hline
\end{tabular}

Hasil penelitian Sukerta (2004) juga menunjukkan peningkatan berat kering oven total tan"' dan ha"1 tanaman sawi pada perlakuan dosis $0 \mathrm{t} \mathrm{ha"1}$ menjadi $10 \mathrm{t}$ ha"' mendapatkan $7,65 \mathrm{~g}$ dan $3,40 \mathrm{t}$ meningkat menjadi 11,42 $\mathrm{g}$ dan 5,08 t. Curah hujan yang tinggi selama percobaan (Tabel 3) menyebabkan kadar air tanah cukup tinggi sehingga tanaman banyak menyerap air, oleh karena itu pertumbuhan tanaman pada perlakuan tersebut hampir sama, seperti yang 
ditunjukkan oleh saat terbentuk krop yang ticlak berbeda diantara perlakuan dosis pupuk kascing (Tabel 2 ). Saat tanaman saling menutupi terjadi pada perlakuan dosis $30 \mathrm{t}^{\text {ha"1 }}$ yang berbeda nyata pada dosis $10 \mathrm{t} \mathrm{ha"}^{\prime \prime}$ (Tabel 2).

Tabel 3. Data curah hujan (mm) 2005-2006 Di Daerali Candikuning

\begin{tabular}{|c|c|c|c|c|c|c|c|c|c|c|c|c|}
\hline Jan & Peb & Mart & Apr & Mei & Juni & Juli & Agt & Sep & Okt & Nop & Des & Jan \\
\hline '05 & '05 & .05 & '05 & '05 & '05 & '05 & '05 & '05 & '05 & '05 & .05 & '06 \\
\hline 215 & 289 & 531 & 450 & 0 & 209 & 44 & 138 & 0 & 326 & 200 & 481 & 712 \\
\hline
\end{tabular}

Sumber: Stasiun penangkar hujan Pos Candikuning, Kecamatan Baturiti Tabanan

Peningkatan dosis pupuk kascing dari 0 sampai 30 t ha"1 meningkatkan diameter krop (Tabel 2). Peningkatan diameter krop ini mengakibatkan peningkatan berat kering oven krop tan"1 dan ha'" (Tabel 4), walaupun berat segar krop tidak berbeda nyata diantara perlakuan dosis pupuk kascing. Sit'at fisik tanah yang semakin baik akibat penambahan pupuk kascing mengakibatkan pertumbuhan akar tanaman menjadi lebih baik sehingga dapat meningkatkan diameter krop (Tabel 2) dan akhirnya meningkatkan berat kering oven krop (Tabel 4 ). Hasil percobaan ini sesuai dengan pernyataan Ismail dan Utomo (1995) bahwa pemberian bahan organik akan menurunkan kepadatan tanah, yang memungkinkan perakaran tanaman berkembang dengan leluasa. Disamping itu tanah juga mempunyai cukup pori dengan kandungan oksigen dan air yang seimbang untuk pertumbuhan. Ini berarti bahwa tanah menjadi lebih gembur dan lebih porous setelah panen adalah karena aktifitas perakaran selama pertumbuhan tanaman. Kemas (2005) menyatakan tanah yang porous berarti tanah cukup meinpunyai ruang pori untuk pergerakan air dan udara masuk keluar tanah secara leluasa, menurut Franklin dkk., (1991) tanah porous dapat mempengaruhi masuknya akar secara leluasa ke dalam rongga tanah yang mana akar berfungsi untuk mengabsorpsi air dan mineral.

Tabel 4. Pengaruh turngal dosis pupuk kascing clan $\mathrm{N}$ terhadap berat kring oven krop $\tan ^{\prime 1}$ dan ha"' indek panen

\begin{tabular}{cccc}
\hline Perlakuan & $\begin{array}{c}\text { Berat kering } \\
\left(\text { gtan"1 }^{\prime \prime}\right.\end{array}$ & $\begin{array}{c}\text { Oven krop } \\
\left(\mathrm{t} \mathrm{ha}^{1}\right)\end{array}$ & $\begin{array}{c}\text { Indek panen } \\
7 c\end{array}$ \\
\hline Dosis pupuk kascing $\left(\mathrm{t} \mathrm{ha"1}^{\prime \prime}\right)$ & $2,480 \mathrm{~b}$ & $0,212 \mathrm{c}$ & $33.97 \mathrm{ab}$ \\
0 & $3,029 \mathrm{a}$ & $0,232 \mathrm{ab}$ & $35,72 \mathrm{a}$ \\
10 & $2.904 \mathrm{a}$ & $0,239 \mathrm{a}$ & $35,57 \mathrm{a}$ \\
20 & $2,783 \mathrm{ab}$ & $0,220 \mathrm{be}$ & $32,23 \mathrm{~b}$ \\
30 & 0,323 & 0,016 & 2,20 \\
\hline BNT 5\% & $2,456 \mathrm{~b}$ & $0,217 \mathrm{a}$ & $33,26 \mathrm{a}$ \\
\hline Dosis N (kg ha"1 $)$ & $2,798 \mathrm{a}$ & $0,232 \mathrm{a}$ & $34,57 \mathrm{a}$ \\
9 & $2,924 \mathrm{a}$ & $0,227 \mathrm{a}$ & $34,17 \mathrm{a}$ \\
138 & $3,017 \mathrm{a}$ & $0,228 \mathrm{a}$ & $35,52 \mathrm{a}$ \\
\hline BNT 5\% & 0,323 & - & - \\
\hline
\end{tabular}

Keterangan: Angka-angka yang diikuti oleh huruf yang sama pada perlakuan dan kolom yang sama adalah tidak berbeda nyata pada uji BNT 5\%.

\section{Hubungan antara Dosis Pupuk Kascing dan Berat Kering Oven Krop ha"1}

Hubungan antara dosis pupuk kascing dan berat kering oven krop ha"1 ${ }^{11}$ adalah berbentuk kuadratik dengan persamaan regresi:
$\mathrm{Y}=0,21135+0,0032 \mathrm{X}-0,000097 \mathrm{X}^{2} ; \mathrm{R}^{2}=$ 0,981. Pada percobaan ini diperoleh dosis pupuk kascing optimum sebesar 16,0 t ha'" dan berat kering oven krop maksimum 0,237 t ha"' (Gambar $1)$. 


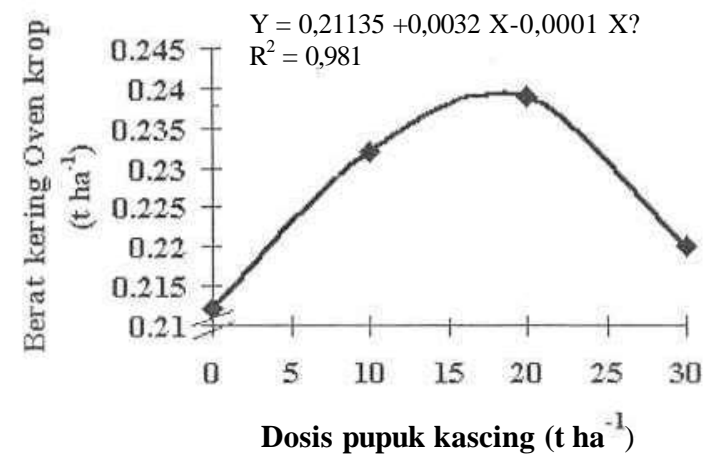

Gambar 1. Hubungan antara dosis pupuk kascing dan berat kering oven krop ha"' Xopt = 16,0 t ha"'; Ymaks $=0,237 \mathrm{t}$ ha"'

Berat kering oven krop ha"' tidak dipertgaruhi secara nyata oleh dosis N (Tabel 4). Berat kering oven krop rata- rata pada perlakuan dosis $\mathrm{N}$ adalah 0,226 t ha"1 (Tabel 4), belum diperoleh dosis $\mathrm{N}$ optimum. Pengaruh dosis $\mathrm{N}$ yang tidak nyata itu disebabkan oleh berat segar krop ha"1 juga tidak secara nyata dipengaruhi oleh dosis N. Pengaruh tidak nyata ciari dosis $\mathrm{N}$ tersebut terhadap ke dua variabel di atas mungkin disebabkan oleh curah hujan yang tinggi selama percobaan (Tabel 3) sehingga unsur $\mathrm{N}$ yang diberikan sebagai perlakuan banyak hiking terutama karena hanyut. Sementara itu, berat kering oven krop tan"! sangat nyata dipengaruhi oleh dosis $\mathrm{N}$ walaupun berat segar krop $\tan ^{11}$ tidak dipengaruhi oleh perlakuan tersebut. Dosis $92 \mathrm{~kg} \mathrm{~N} \mathrm{ha"1} \mathrm{meningkatkan} \mathrm{nilai} \mathrm{variabel}$ tersebut sebesar 13,9 \% dibandingkan tanpa pemberian $\mathrm{N}$ dan dosis $\mathrm{N}$ yang lebih tinggi dari $92 \mathrm{~kg} \mathrm{~N}$ ha"1 memberikan nilai yang tidak berbeda nyata. Hal ini menunjukkan bahwa dosis $\mathrm{N}$ tersebut sudah cukup memenuhi kebutuhan tanaman karena kandungan N-total tanah percobaan sudah tergolong sedang $(0,27$ $\%$ ) (Tabel 1). Meskipun berat kering oven krop $\tan ^{\prime 1}$ sangat nyata meningkat dengan pemberian $92 \mathrm{~kg} \mathrm{~N}$ ha"1, tetapi karena beberapa tanaman dalam ubinan ada yang tidak seragam pertumbuhannya maka berat kering oven krop ha" ${ }^{\prime 1}$ tidak meningkat (Tabel 4). Tidak seragamnya pertumbuhan tanaman adalah karena banyaknya penyulaman yang dilakukan terutama pada stadia awal pertumbuhan tanaman akibat pukulan hujan. Hal ini menyebabkan lambatnya pertumbuhan tanaman yang disulam sehingga tanaman lebih kecil dibandingkan tanaman yang tumbuh normal (bukan sulaman).

Berat kering oven krop ha"' tidak dipengaruhi secara nyata oleh dosis $\mathrm{N}$ ( Tabel 4). Hal ini mengakibat nilai indeks panen juga tidak dipengaruhi oleh dosis N. Indeks panen rata- rata pada perlakuan dosis $\mathrm{N}$ adalah $34,38 \%$ (Tabel 4). Ini menunjukkan bahwa asimilat hasil proses fotosintesis hanya kurang lebih sepertiga yang dialokasikan ke krop.

\section{SIMPULAN}

Dosis pupuk kascing berpengaruh nyata terhadap saat tanaman saling menutupi, diameter krop, berat kering oven krop tan"' dan ha"1. Peningkatan dosis pupuk kascing dari 0 menjadi $10 \mathrm{t}$ ha" ${ }^{11}$ memberikan berat kering oven krop sebesar 0,232 $\mathrm{t}$ ha"' , yaitu meningkat sebesar 9,43 $\%$.

Dosis $\mathrm{N}$ hanya berpengaruh nyata terhadap berat kering oven krop tan' ${ }^{\prime}$. Peningkatan dosis N dari 0 menjadi $92 \mathrm{~kg} \mathrm{~N}$ ha"' memberikan berat kering oven krop sebesar 2,798 g tan"' atau meningkat sebesar $13,9 \%$.

Hubungan antara dosis pupuk kascing dengan berat kering oven krop ha"' adalah berbentuk kuadratik $(\mathrm{Y}=0,21135+0,0032 \mathrm{X}$ $\left.0.0001 \mathrm{X}^{2} ; \mathrm{R}^{2}=0,981\right)$. Pada percobaan ini diperoleh dosis pupuk kascing optimum sebesar 16,0 t ha"' dan berat kering oven krop maksimum sebesar 0,237 t ha"l, tetapi sebaliknya belum diperoleh dosis $\mathrm{N}$ optimum.

\section{UCAPAN TERIMA KASIH}

Pada kesempatan yang baik ini penulis ingin mengucapkan terimakasih kepada semua pihak yang telah membantu penulis dalam penelitian dan penulisan ini, terutama kepada Ibu Prof. I.G.A Mas Sri Agung dan Bapak Prof. D.K. Suanda.

\section{DAFTAR PUSTAKA}

Anonimus, 2004. Laporan luas panen dan produksi selada lahun 2004. Tabanan : 
Cabang Dinas Pertanian Kecamatan Baturiti Tabanan

Buckman. H.O., Brady. N.C. 19S2. Ilmu Taiuih. Jakarta: Bhatara Karya Aksara.(terjemahan)

Franklin, P. 0., Brent, P. R., Roger, L. M. 1991. Fi.siologi Tanaman Budidaya. Jakarta: Universitas Indonesia (terjemahan)

Gomez. K.A.. Gomez, A.A. 1995. Proseditr Stali.stik uiituk Pcnelitian Pertanian. Jakarta : Universitas Indonesia (terjemahan)

Haryanto, E., Tina, S.,Estu,R., Hendro.S. 2003. Sawi \& Selada. Jakarta : Eds Rev. Penebar Swadaya

Ismail, T., Utomo, W. H. 1995. Hubimgaii Tanah, Air dan Tanamun. Semarang : Institut Keguruan dan Ilmu Pendidikan.

Karnata, N .2004. Pengaruh Waktu Tanam clan Jenis Pupuk Organik Terhadap Perlumbuhan dan Hasil Kentang (Sotamun tuberosum L.) di Lahan Kering Beriklim Basah (tesis). Denpasar: Universitas Udayana

Kartini, N. L. 2000. Pertanian Organik sebagai Pertanian Masa Depan. Presiding Seminar Nasional Pengembangan Teknologi Pertanian Dalam Upaya Mendukung Ketahanan Pangan Nasional. Bogor : Pusat Penelitian dan

\begin{tabular}{|c|c|c|}
\hline Pengembangan & Sosial & Ekonomi \\
\hline Pertania & & dan \\
\hline $\begin{array}{l}\text { Pengembangan } \\
\text { Pertanian }\end{array}$ & Pertanian & eparte \\
\hline
\end{tabular}

Kemas, A. H. 2005. Dasar- clasar Ilmu Tanah. Jakarta: PT Raja Grafindo Persada

Mulat, T. 2003. Membitat dan Meimmfaatkan Kascing Pupuk Organik Berkualitas.

Cetakan pertama. Jakarta : PT. Agro Media Pustaka.

Nurhayati, H., Nyakpa, M.Y., Lubis, A. M., Nugroho, S. G., Saul, R., Amin, D. M., Go Ban Hong., H. H. 1986. Dasar dasar limit Tanah. Lampung: Universitas Lampung

Rukmana, R. 1994. Bertanain Selada dan Andewi. Yogyakarta : Penerbit Kanisius

Sukerta, M. 2004. Pengaruh Dosis Nitrogen dan Pupuk Kascing terhadap Pertumbuhan dan Hasil Tanaman Sawi Hijau (Brassica juncea L.) di Lahan Kering, Desa Jungutbatu Nusa Lembongan, Kabupaten Klungkung. (tesis). Denpasar : Universitas Udayana "

Untung, K. 1997. Peranan Pertanian Organik dalam Pembangunan yang berwawasan Lingkungan. Jakarta : Seminar Nasional Pertanian Organik. Yayasan Bumi Lestari. 